\title{
Serious Games in Preschool and Primary Education: Benefits And Impacts on Curriculum Course Syllabus
}

\author{
https://doi.org/10.3991/ijet.v12i01.6065 \\ George P. Papanastasiou \\ National Center For Scientific Research "Demokritos", Athens, Greece \\ gpapanasta@gmail.com \\ Athanasios S. Drigas \\ National Center For Scientific Research "Demokritos", Athens, Greece \\ drait.demokritos.gr \\ Charalabos Skianis \\ University of the Aegean, Samos, Greece \\ cskianis@aegean.gr
}

\begin{abstract}
Serious Games (SGs) indicate positive effects on Preschool and Primary school students and promote a multi sensory style of learning. This review paper explores the integration of Serious Games in the area of Preschool and Primary Education, in the last decade (2006-2016). The studies were carried out on Preschool and Primary school settings, respectively. Research showed that Serious Games are able to keep all students engaged in classroom facilities, scaffolding their learning through increased motivation, independence, autonomy and resultant self-esteem. Serious Games Based Learning (GBL) has proven its added value in almost every aspect of the curriculum.
\end{abstract}

Keywords - Serious Games, curriculum, motivation, games-based learning, interactive technologies

\section{$1 \quad$ Introduction}

High levels of early school leaving (ESL) and drop-out from initial Vocational Education and Training (i-VET) are two Europe 2020 key challenge strategies which are addressed to meet employment targets and take actions to prevent social deprivation, unemployment and poverty. For that reason, four countries conducted a project, called the Code Red. Following the information and the analysis of the actual stakeholders' needs, the participating countries co-designed a serious games methodology and implemented digital educational game prototypes aiming at engaging young people in an interactive (participatory) skills' acquisition process. The Code Red project methodology proved to be a very enjoyable process for all participants, trainers, trainees and facilitators, creating a good grounding for the development of desktop and mobile games to act as an e-learning environment and increase accessibility [1]. 
Furthermore, according to a survey of over 1,600 practicing classroom teachers in English state primary and secondary schools, the majority of them believe that computer games can help support children's motor and cognitive development (83\%), their ICT skills (73\%), and their higher-order thinking skills (such as logical thinking, planning and strategizing) (65\%). The skills of successful gaming are seen as an interrelated set of skills and competences enhancing a range of other skills, including web research, persistence in solving challenging problems, information processing, communication, creative production, peer support and assistance for the good of the whole class. Games can be social, maintaining friendship networks not simply restricted to virtual interactions, but also while exchanging hints and tips with one another for better progressing, where they provide a safe environment to both winning and, crucially, to losing. This aspect of game-based learning to enhance relationships between students, as well as between students and their teachers, working together as 'partners in learning', is a key priority to enhance young people's 'constructionist' learning and ' $21^{\text {st }}$ century skills' [2].

According to Dr Sara de Freitas (2010), "the advantage of the 'serious games approaches' lie in their ability to create dedicated game content for learning purposes", despite the skepticism about its efficacy as a learning tool. Three main user groups tutors of ICT skills, learners on ICT skills courses, and experts such as educationalists, game specialists, and developers, who were interviewed either from a distance or face to face workshop activities, were more engaged by games and simulations than by traditional text-based approaches to learning. Their comments indicated that games give students variety and some fun whilst reinforcing their learning, improve computer skills, provide learners with the ability to work at their own pace, and support visual/kinaesthetic learning. At the same time, the following key issues have arisen from the study: Increased motivation levels of learners, Potential for widening participation, Use of collaborative learning, and Efficacy of learning through experience. The author concludes that the advantage of the 'serious games' approaches as learning tools lie in their ability to create dedicated game content for learning purposes, supporting exploratory learning in and between formal and informal contexts and supporting practitioners attempting to use them to engage and/or excite their learners [3].

SGs provide enjoyment, pleasure, motivation, gratification and emotion within a safe environment for active, critical and creative learning, allowing users to explore skills, methods and concepts. A SG is a game in which learning is the primary goal, having a personalized structure for either individual users or groups. The definition of story board and graphical design elements of the GBL solution in line with the selected pedagogical approach and the instructional design is a critical aspect of SGs development [4]. Design of game formats in fields of advanced technologies such as Artificial Intelligence, Human-Computer Interaction, modeling and simulation, neuroscience and virtual reality might join effectively educational and entertainment goals [5].

Serious games are considered as key structures for the educational practices and infrastructure over the coming years where their potential offers a paradigm shift in how education and training are delivered in the $21^{\text {st }}$ Century. The shift will include multimodal interfaces, brain-computer interfaces and haptics using avatar driven scaffolded approaches, with an emphasis upon social interactive learning that can be used effec- 
tively as metaphors for achieving behavioral and attitudinal changes. Serious games are a new and emerging sector of the games industry that involves all the stakeholders: educationalists, game designers and developers, researchers and centrally the learners [6].

De Freitas and Oliver (2006), introduced the four-dimensional framework with which game designers would identify a better fit between the needs of the curriculum and the best form of use of the game to mediate the learning activities and promote increased reflection upon context, pedagogy, mode of representation and learner specification. Their approach help tutors to be more critical about how they embed games and simulations into their lesson plans and learners to benefit from more self-directed and differentiated learning. The first dimension refers to the particular context where play/learning takes play, the second to the attributes of the particular learner, the third to the internal representational world - or diegesis- of the game or simulation, and the fourth in the process of learning. The four dimensions could facilitate the practitioner's flow between the different visualizations addressing more critical and reflective process for embedding games and simulations in teaching practice [18].

\section{Serious Games' Impact on Reading And Writing}

Alice J. Robinson (2008), argues that video games can provide a framework for thinking about writing and the teaching of writing. She states that the theory and practice of a play experience are a designed space with a strong analogy with the design of composition curricula and course syllabi, which has enormous implications for learning and literacy. Thus, it makes sense of our questions about video games' significance as places for literacy to meet the need of all and generate an interactive experience. In this view, designers and developers design documents and creative processes with principles surprisingly similar to the principles of creating any successful curriculum, especially in the area of written composition [7].

Computer gaming in the composition classroom can be enacted in a practical way to better teach writing in a pedagogy form of play that emphasizes active participation, leading to the production of rhetorical texts for a gamespace community. Gamers learn as they play, solving puzzles, learning strategies, becoming immersed in their writing while staying within the constraints of the game world, transforming the writing classroom from workspace to gamespace. Emergent gameplay pedagogy highlights play as an important part of the writing process, helping students creatively discover problems and rhetorical solutions within the game space, as they consider both academic and professional options for writing [8].

\section{Serious Games' Impact on Geometric and Mathematical Thinking}

GeoCAL, a multimedia software program, was used in an experimental study to explore its learning effects on each of the geometric thinking levels (recognition, 
visual association, description/analysis, and abstraction/relation) and on overall geometric thinking. The children using the structured activities of the software design, are able to recognize simple geometric patterns, recognize types of geometric shapes, identify attributes of geometric shapes, make more meaningful categorizations of geometric shapes, and finally are able to use verification, induction, inference, etc., concerning geometric principles. Learning activities such as Jigsaw puzzle, shape tracer, stamping, shadow matching, arranging matchsticks, cargo, identifying cards, and classification box were used to test the learning effects of GeoCAL for elementary students. The results demonstrate that although GeoCAL activities does not produce significant learning effects on recognition ability it helps students develop visual association's ability. Also, provides interactive operating modes that enhance students' abilities to analyze and describe shapes, and produces significant improvements on inference and induction abilities. GeoCAL has proved its added value on the development of overall geometric concepts of second grade elementary school students [13].

The results of a mixed-method approach developed by the Center for Advanced Technologies of a school district, engaged learning from gameplay to reinforce academic standards for mathematics and facilitate elementary students' cognitive math achievement and metacognitive awareness. In this case study, eight web-based mathematics games were developed using Macromedia Flash and targeting a variety of math skills, such as measurement, comparing whole numbers, solving simple equations, and mapping $X$ and $Y$ coordinates. After five-week computer math drill gaming, study findings indicated the development of positive attitudes toward math learning even though being more simplistic than commercial role-playing games in terms of visual, activity and interaction design [11].

In another study, the researchers explored whether improving skills in the visualmotor and working memory domain by game play, might enhance arithmetic performance and to what extent. Therefore, they compared the results of a math test, before and after game training and that of a traditional training by means of math paper exercises, whose contents were perfectly matched both in the game training and the traditional training. Results indicated higher accuracy percentages in post test when compared with the pretest session for the group that played the educational game, implying a stronger learning effect for the students who did the computer math test comparing with those who did the paper math drills. Also, the results showed that describing the game versus math drills experience, a higher proportion of children selected the attribute 'exciting' for their game playing experience and, likewise a higher proportion of the group that solved the paper math exercises selected the attribute 'boring' [12].

Drigas and Pappas (2015), in their review paper, examined the most representative studies over the last decade which evaluate the effects of video games on mathematics achievement and showed how video games support children's mathematic comprehension on fundamental concepts. Also, they investigated the different types of Online video games such as Educational Math Games, Adventure Games, Simulation Games and Mobile Video Games as well as Computer Video Games like Simulation 
Paper-Serious Games in Preschool and Primary Education: Benefits And Impacts on Curriculum Course Syllabus

Games, Srategy Games and Role-Playing Games presenting their positive effect on student's mathematical skills [16].

\section{Serious Games' Impact On Strategic And Reasoning Abilities}

In a long-term pilot project, Bottino, R. M., Ferlino, L., Ott, M., \& Tavella, M. (2007), performed a qualitative analysis of some of the cognitive processes involved in playing with a number of computer games, mainly those usually called mind games highlighting possible pedagogical values which foster transversal reasoning skills that can be used not only at school, but also in extracurricular and home activities. In parallel, a quantitative evaluation of children's performance with the computer games was performed. Although the findings are not generalizable, they do offer insights underpinning basic strategic and reasoning skills such as task comprehension of the objective to be attained and construction of a solution strategy to use effectively the available tools and their functional characteristics. The development of reasoning abilities originates from the ability to understand and manipulate the games' interface features and the synergy between the learning process and the student's interaction with the software. The construction of a solution strategy is based on anticipating skills that prefigure the consequence of an action either coming from his/her moves or the opponent's. Thus, computer games support cognitive processes in a way that is unavailable with traditional tools, following software features such as: Direct feedback on the player's actions, Backtracking the possibility to retrace one's steps, Support in the detection of the most favourable cases, Suport for anticipation, Support for memorization of specific actions, Graduation in the level of difficulty and Specific tips on demand. [14].

Moreover, the results of another study suggest that constructing a game with an authentic, complex and meaningful context might be a better way to enhance student motivation and deep learning than simply playing an existing game. The study investigated the effects of interactive computer-based tasks on learning with regard to students' intrinsic motivation and deep strategy use. According to the research, a significant difference showed between the 'drag and drop' game construction condition and the memory game playing condition, in favor of the construction condition for both intrinsic motivation and deep strategy use. The construction task might have been more authentic or more meaningful than playing a game and invokes students' activity more [15].

\section{Serious Games' Impact on Critical Thinking, Problem Solving and Creativity}

MinecraftEdu is a highly effective, popular video game that provides students with the freedom to create, fosters their development of critical thinking and problem solving skills and facilitates their communication and collaboration skills. The open-ended sandbox design aspects of the game personalize the curriculum, strengthen executive 
functioning skills and teach students how to be successful learners. Setting strict play time rules, basic or bigger goals and re-creating something from the real world encourages deep learning and allows for players to learn the complex skill of coding and valuable life lessons [9].

The video game world has embraced the constructivist view of learning which considers the learner as an active processor of information and not just an active recipient of it, as for behaviourism. Modeling the construction of knowledge, reflecting the learner's thinking, formatting playing strategies, scaffolding children's thinking exploration, debriefing and articulating knowledge with their peers are techniques that would determine how constructivistic a game could be [10].

Simulations and strategic games allow students to learn basic skills that alleviate the problem between stored and applied knowledge that students face with factual knowledge which is detached from practice. These games, named epistemic games, focus on children's expertise, professional-like skills, and innovative thinking rather than on their performance on basic and routine skills. By playing epistemic games, young children learn to see the world, solve its problems in multiple ways and step outside what is usual. Schools and educators need to realize that schooling is completely interwined with social station preparing children and young people for responsible citizenship and achieving their full potential. Epistemic games include eclectic features from both curricula; those that immerse children in rich learning activities and those that stress telling them what they need to know, not allowing much room for building expertise and innovation [26].

Problem solving orchestrates every day cognitive, metacognitive and behavioral situations and constitutes a moderator for coordinating competetences needed in these cases. Immersive problem-based tasks as well as individualized and cooperative learning experiences deriving from the implementation of effective serious game techniques develop preschool and primary school students' problem solving ability and academic achievement [27].

\section{Serious Games' Impact on Geography Learning}

In a study about geography learning, researchers designed and developed a threedimensional educational computer game, and they found that computer games can be utilized in formal learning environments to support students in learning about geography. In relation to the qualitative results, players had high expectations for the game environment, and became familiar with the shape of countries, places of interest in them, population and language of countries, and other cultural characteristics. In regard to the quantitative results it was found that students demonstrated statistically significant higher intrinsic motivations and statistically significant lower extrinsic motivations while participating in the game-based activities. Finally, it was confirmed that computer games provide the characteristics of an authentic and relevant learning environment and increase learner's autonomy fostering exploration, interaction, collaboration, and immersion in geography education, while making learning fun [17]. 


\section{$7 \quad$ Serious Games' Impact on Science Courses}

Sung and Hwang (2012), developed a collaborative educational computer game, based on a grid-based Mindtool to guide students to organize what they have learned during the gaming-playing process. Three classes of sixth graders of an elementary school constituted the experimental design (Experimental group, Control group A, Contorl group B) to evaluate the effectiveness of the proposed approach: differentiating a set of target plants for the subject unit "Identifying the plants of the school campus". The experimental results indicated that the game-based learning approach improved learning achievements of the experimental group students, improved their learning attitudes toward science, had a significant impact on improving the student's learning motivation in the natural science course, enhanced their self-efficacy of using computers to learn, and their confidence in learning collaboratively with their peers. Most of them also shared the feeling that the use of the shared repertory grid was helpful to them in exchanging information in an efficient way, owing to the provision of the knowledge organizing and sharing facility embedded in the collaborative gaming environment [19].

In a review of empirical studies on the use of Serious Games (SGs) in science education, a series of content analyses were conducted which identified the following research trends, among others: a surge of interest in the use of SGs in science education. Knowledge construction was the major learning goal of these SGs. SGs can be an effective and powerful tool for combining science learning with enjoyment. The coding scheme of the research framework consisted of three dimensions, namely, game, pedagogy, and research method, which were used as a lens to get a complete picture of the advancements and trends in using SGs in science education from 2002 to 2013. The SGs were categorized due to their gaming features as follows: adventure game or role-playing game, simulation game, puzzle game, strategy game, action game, fighting game or platform. The pedagogical dimension was analysed in terms of the following aspects: Subject domain, Educational theoretical foundation, instructional strategy, Pedagogical role of SGs. Finally, the research methodology was analysed in terms of the following aspects: Participants, Research method, and Research foci. Dimensions, sub-dimensions and categories of the coding scheme were generated by a grounded theory that employs social interactions and collaborative learning as a crucial factor not only on participants' learning outcomes but also on relations between science educators, science instructors and SGs designers [20].

Minecraft is a multiplayer sandbox video game (analogous to Lego construction sets) having a functioning ecology, with chemistry, biology, physics, geology, geography and mathematical aspects that are able to be modelled in the classroom to develop the scientific literacy of players. For example, in Biology, in a minecraft map designed around the human body students are immersed in a visual 3-dimensional environment to move and place blocks in order to mimic cellular activity. In the area of Ecology, the map generator of minecraft creates biomes and displays different heights, temperatures, humidities and foliage. In physics the game simulates virtually almost every situation of real life. In Chemistry, which perhaps is not the strongest component of the game, students with the help of their teachers may experience a 
basic states of matter and phase change simulation (solid, liquid, gas) as well as explore a 3-dimensional periodic table of the elements. In Mathematics and Geometry, the game puts forward the most obvious mathematical and geometrical concepts such as the four operations and the generation of circles respectively. Furthermore, it is possible to experiment with algebraic formulas, measurements of perimeter, area and 3-dimensional images. In Geology and Geography, the game generates cliffs, hills, mountains and ravines as well as beaches next to oceans or lakes. The ability to configure a map using data imported from a Geographical Information System (GIS) gives the possibility to model any location on the Earth's surface. A Minecraft world can be a game-changer in the field of science instruction addressing the opportunity for collaborative lesson design between instructors [28].

\section{$8 \quad$ Serious Games' Impact on Language Learning}

In their Serious Game research project (Mingoville universe platform), Sørensen and Meyer, focus on the exploration and development of game based prototypes for language teaching and learning and produce credible knowledge about the benefits and outcomes of serious games. The serious game they developed, is based on the idea that children learn and are motivated by problem solving and game activities, exploiting the 'fun-factor' of gaming structured around themes and activities. The missions aim at vocabulary training, spelling and word recognition as well as create narratives, draw pictures or sing karaoke in English, construct sentences and the most popular activity where children are interviewed by one of the course characters. Thus, the language is learned on a confident basis targeting at specific competences and curriculum goals with familiar objects from school and from the context of the home as well as games that are familiar to the children. This paper describes a game-based concept for teaching languages in primary school that allows children to perform within their own categories of achievement and invite learners to participate in creating knowledge and performing expertise in protected linguistic environments [21].

In another article, the designers of the previous platform suggest that it exploits the 'fun-factor' of gaming where narratives and intrinsic motivation are crucial factors in language learning and school activities such as reading, writing, listening and spelling rather than traditional skills-based and textbook based material focusing on the same aspects respectively. This research analysis of the Mingoville platform has shown that when games are used for language learning in the framework of a Computer Assisted Language Learning (CALL) children are motivated to learn languages as well as seamlessly integrate learning contexts and game narrative to create a complete learning situation. Thus, the game design must be intrinsically motivating, incorporating a fantasy theme the target user is interested in and stimulates him through curiosity. Therefore, an important challenge involved in designing and conceptualising serious games for language learning is that the "seriousness' of games can support curriculum aims and goals such as the use of interactivity, collaboration and exploration based simulations for teaching English in primary school [22]. 
Ang and Zaphiris (2008), wrote a research chapter in which they discussed and examined theoretical issues and practical challenges in game-based language learning to provide an overview of the natural learning process that happens within the educational game technologies of a CALL activity. This approach stresses meaningful interaction in authentic discources and attempts to integrate learners in authentic environments in which computers are seen as artefacts that could mediate human interaction. The 'reader' is gradually learning to take meaningful actions and see the result of his decisions enacting his own stories instead of being a passive reader. The researchers believe that the increasing capability of graphic processing encourages the creation of player-game verbal interactions, which are closer to reality and related to linquistic skills the player must acquire to proceed in the game [23].

Griva Eleni, Klio Semoglou, and Athina Geladari (2010), conducted a pilot early Foreign Language (FL) project on a game-based context launched in two second grade primary school classrooms, in Greece. The intervention of the project was based on cooperation, competition, verbal interaction, active participation, and enjoyment through interactive simulation and physical activity involvement. In the first phase of the project the students were encouraged to play with words in meaningful contexts participating in simple games to develop vocabulary and acquire very basic oral skills, given adequate opportunities to interact with the teacher and the peers. In the second phase of the project, the main purpose was to make the students to 'produce' the language and communicate through role play and physical activities without worrying if they are doing right or wrong. The results of the project showed positive effects on children's oral skills development in English as a foreign language (EFL). Furthermore, student's motivation and participation in the games promoted better than the control group. Adopting game-based teaching methods in English Language lessons for children in their first years of primary education 'produced' a more relaxed atmosphere and reduced the students' tension and anxiety during learning, making them feel confident to develop communicative competence [24].

Game based strategies have been considered from both educators, researchers, teachers and students as a perfect method to acquire motivation and engagement in language learning. Anyaegbu, Ting, and Li carried out a report in two primary schools in the integration of Serious Games to motivate the Chinese primary students in EFL (English as a Foreign Language) classrooms and identified the different factors that Mingoville affected the students' full motivation. The researchers concluded that the integration of Mingoville games in an EFL classroom, if properly organized, improves the Chinese students' classroom atmosphere, lowers students' anxiety, motivates and sustains their interest in learning ESL (English as a Second Language) and helps them learn and retain the language with new words, pronunciation, writing and listening, all in a fun way [25].

\section{Conclusions}

The emerging movement identified as Serious Games aims to meet the needs of a new generation of learners that use digital devices frequently to communicate, express 
themselves, and understand the world around them. Digital games possess intrinsic learning qualities that challenge and foster pupils who are pragmatically minded to learn by doing, learn from their peers and improve their skills. Digital games are based on the principle that playing is learning in a challenging environment where students can make mistakes and experiment with them involving a process of trial and error. Although early educational software placed an emphasis on the behaviorist and cognitivist theories of learning, recent digital games encourage a contructivist approach, where players can readjust their knowledge and skills accordingly. One of the foremost quality features of digital games is their capacity to include a rich variety of auditory, tactile, visual and intellectual stimuli that triggers students' motivation to focus on the task and increase learners' familiarity with thematic concepts. Therefore, it is essential to link game concepts to real life, explaining key actions in the digital game that mirror real life concepts: What is the main topic of the game? What did you learn from the game? What is the goal of the game? What do you need to do to be successful in this game? What would happen if...? In this regard digital games provide an additional way to motivate children to understand topics through play that they might otherwise find too complicated [29].

The challenges in embedding serious games into formal education lie in their ability to demonstrate the complexity and iterconnectedness of issues. These challenges can be approached through the use of three frameworks, namely the identification of learning goals, identification of teaching enhancement and game assessment. In the area of pedagogy the learner needs to be active while playing rather than being cognitively overloaded. Game worlds need to be coherent and consistent and the learning objectives need to be understood by the player [30].

Games, in fact, teach children complex task and abilities and result in the way players see the world and process information that enhance learning. A proper level of difficulty keeps individuals right at the edge of their ability, providing several usercontrolled difficulty settings. Action video games promote a model of how to teach children complex and difficult tasks and abilities, representing a form of play that can be harnessed for serious good, namely improvements in a wide variety of perceptual, attentional, and cognitive abilities [31].

SGs provide learners' enjoyment, pleasure, motivation, ego gratification and emotion changing where, what and how they learn. Games facilitate immersion and active user involvement, whilst they need content and pedagogy expertise, design research and impact research. Player motivation and engagement are critical to the success of the SGs therefore the game design is dependent on the learning objective, the intended user group and under what circumstances the game will be used [32].

Thus, there is a need for a well-established and appropriate implementation of instructional principles to provide a common ground for game designers and educators to collaborate and effectively incorporate games into the curricula. The game design must encompass all three learning domains: cognitive, affective and psychomotor, if content learning is to take place as a result of playing serious games [33]. 
Paper-Serious Games in Preschool and Primary Education: Benefits And Impacts on Curriculum Course Syllabus

\section{References}

1. MILIS, George, et al. "Addressing Early School Leaving And Disengagement From Education Through Serious Games' Co-Design." eLearning \& Software for Education 2, 2015

2. Williamson, Ben. Computer games, schools, and young people: A report for educators on using games for learning. Bristol: Futurelab, 2009

3. De Freitas, S. I., Using games and simulations for supporting learning. Learning, media and technology, 31(4), 343-358, 2006 https://doi.org/10.1080/17439880601021967

4. Protopsaltis, A., Pannese, L., Hetzner, S., Pappa, D., \& de Freitas, S."Creative Learning with Serious Games." iJET 5.SI3, 4-6, 2010

5. De Gloria, Alessandro, Francesco Bellotti, and Riccardo Berta. "Serious Games for education and training." International Journal of Serious Games 1.1, 2014

6. De Freitas, Sara, and Fotis Liarokapis. "Serious games: a new paradigm for education?." Serious games and edutainment applications. Springer London, 9-23, 2011

7. Robison, Alice J. "The design is the game: Writing games, teaching writing." Computers and Composition 25.3: 359-370, 2008 https://doi.org/10.1016/j.compcom.2008.04.006

8. Colby, Rebekah Shultz, and Richard Colby. "A pedagogy of play: Integrating computer games into the writing classroom." Computers and Composition 25.3: 300-312, 2008 https://doi.org/10.1016/j.compcom.2008.04.005

9. Risberg, Cathy. "more than Just a Video Game: tips for Using minecraft to personalize the Curriculum and promote Creativity, Collaboration, and problem Solving." IAGC JOURNAL FOCUS: CREATIVITY, CRITICAL THINKING, AND CURRICULUM : 44, 2015

10. Obikwelu, Chinedu, and Janet C. Read. "The Serious Game Constructivist Framework for Children's Learning." Procedia Computer Science 15: 32-37, 2012 https://doi.org/10.1016/ j.procs.2012.10.055

11. Ke, Fengfeng. "A case study of computer gaming for math: Engaged learning from gameplay?." Computers \& Education 51.4 1609-1620, 2008

12. Castellar, E. N., All, A., De Marez, L., \& Van Looy, J., Cognitive abilities, digital games and arithmetic performance enhancement: A study comparing the effects of a math game and paper exercises. Computers \& Education, 85, 123-133, 2015 https://doi.org/10.1016/ j.compedu.2014.12.021

13. Chang, Kuo-En, Yao-Ting Sung, and Song-Ying Lin. "Developing geometry thinking through multimedia learning activities." Computers in Human Behavior 23.5, 2212-2229, 2007 https://doi.org/10.1016/j.chb.2006.03.007

14. Bottino, R. M., Ferlino, L., Ott, M., \& Tavella, M., "Developing strategic and reasoning abilities with computer games at primary school level." Computers \& Education 49.4, 1272-1286, 2007 https://doi.org/10.1016/j.compedu.2006.02.003

15. Vos, N., Van Der Meijden, H., \& Denessen, E. Effects of constructing versus playing an educational game on student motivation and deep learning strategy use. Computers \& Education, 56(1), 127-137, $2011 \mathrm{https://doi.org/10.1016/j.compedu.2010.08.013}$

16. Drigas, Athanasios S., and Marios A. Pappas. "On line and other Game-Based Learning for Mathematics." International Journal of Online Engineering (iJOE) 11.4, 62-67, 2015 https://doi.org/10.3991/ijoe.v11i4.4742

17. Tüzün, H., Yılmaz-Soylu, M., Karakuş, T., İnal, Y., \& Kızılkaya, G. The effects of computer games on primary school students' achievement and motivation in geography learning. Computers \& Education, 52(1), 68-77, 2009 https://doi.org/10.1016/j.compedu. $\underline{2008.06 .008}$ 
18. De Freitas, S., \& Oliver, M., How can exploratory learning with games and simulations within the curriculum be most effectively evaluated?. Computers \& education, 46(3), 249264, 2006 https://doi.org/10.1016/j.compedu.2005.11.007

19. Sung, H. Y., \& Hwang, G. J., A collaborative game-based learning approach to improving students' learning performance in science courses. Computers \& Education, 63, 43-51, 2013 https://doi.org/10.1016/j.compedu.2012.11.019

20. Cheng, M. T., Chen, J. H., Chu, S. J., \& Chen, S. Y., The use of serious games in science education: a review of selected empirical research from 2002 to 2013. Journal of Computers in Education, 2(3), 353-375, 2015 https://doi.org/10.1007/s40692-015-0039-9

21. Sørensen, B. H., \& Meyer, B.,Serious Games in language learning and teaching-a theoretical perspective. In Proceedings of the 3rd international conference of the digital games research association (pp. 559-566), 2007

22. Meyer, B., \& Sørensen, B. H., Designing serious games for computer assisted language learning-a framework for development and analysis. In Design and use of serious games (pp. 69-82). Springer Netherlands, 2009 https://doi.org/10.1007/978-1-4020-9496-5 5

23. Ang, C. S., \& Zaphiris, P., Computer games and language learning. Handbook of Research on Instructional Systems and Technology. Hershey, PA: IGI Global, 2008

24. Griva, Eleni, Klio Semoglou, and Athina Geladari. "Early foreign language learning: Implementation of a project in a game-based context." Procedia-Social and Behavioral Sciences 2.2: 3700-3705, $2010 \mathrm{https://doi.org/10.1016/j.sbspro.2010.03.575}$

25. Anyaegbu, R., Ting-JESSY, W., \& Li, Y. I., Serious game motivation in an EFL classroom in Chinese primary school. TOJET: The Turkish Online Journal of Educational Technology, 11(1), 2012

26. Nodoushan, M. A. S., The Shaffer-Gee perspective: Can epistemic games serve education?. Teaching and Teacher Education, 25(6), 897-901, 2009 https://doi.org/10.1016/ j.tate.2009.01.013

27. Drigas, A., \& Karyotaki, M., Online and other ICT-based Assessment Tools for Problemsolving Skills. International Journal of Emerging Technologies in Learning (iJET), 11(04), 56-60, 2016 https://doi.org/10.3991/ijet.v11i04.5339

28. Short, D., Teaching scientific concepts using a virtual world-Minecraft. Teaching Science-the Journal of the Australian Science Teachers Association, 58(3), 55, 2012

29. Felicia, Patrick. "Digital games in schools: Handbook for teachers.", 2009

30. Ulicsak, M., Games in education: serious games: A Futurelab literature review. FutureLab, 2010

31. Eichenbaum, A., Bavelier, D., \& Green, C. S., Video games: Play that can do serious good. American Journal of Play, 7(1), 50, 2014

32. Pappa, D., \& Pannese, L., Effective design and evaluation of serious games: The case of the e-VITA project. In Knowledge Management, Information Systems, E-Learning, and Sustainability Research (pp. 225-237). Springer Berlin Heidelberg, 2010

33. Gunter, G. A., Kenny, R. F., \& Vick, E. H., A case for a formal design paradigm for serious games. The Journal of the International Digital Media and Arts Association, 3(1), 93105,2006

\section{Authors}

George Papanastasiou is a fellow Researcher at IIT NCSR Demokritos and a teacher for students with special education needs. He is currently working on his $\mathrm{PhD}$ on Serious Games and Game Based Learning for students with Executive Control 
Disabilities. His research areas include Gaming in the classroom, Motivation and Differentiated instruction with the contribution of ICTs. (e-mail gpapanasta@gmail.com).

Athanasios Drigas is a Research Director at IIT N.C.S.R. Demokritos. He is the Coordinator of Telecoms Lab and founder of Net Media Lab since 1996. From 1985to 1999 he was the Operational manager of the Greek Academic network. He has been the Coordinator of Several International Projects, in the fields of ICTs, and eservices (e-learning, e-psychology, e-government, e-inclusion, e-culture etc). He has published more than 270 articles, 7 books, 25 educational CD-ROMs and several patents. He has been a member of several International committees for the design and coordination of Network and ICT activities and of international conferences and journals. (email: dr@iit.demokritos.gr).

Charalabos Skianis is currently Associate Professor in the Department of Information and Communication Systems at the University of the Aegean in Samos, Greece. He holds a PhD degree in Computer Science, University of Bradford, United Kingdom and a BSc in Physics, Department of Physics, University of Patras, Greece. His current research activities take upon Novel Internet Architectures and Services, Cloud Computing \& Networking, Energy \& Context aware Next Generation Networks and Services, management aspects of mobile and wireless networks, ubiquitous and pervasive computing and End-to-End Quality of Service provisioning in heterogeneous networks environment. (e-mail cskianis@aegean.gr)

Submited 20 July 2016. Published as resubmitted by the authors 23 October 21016 . 